\title{
A RELAÇÃO DOS DISTRIBUIDORES COM UMA MARCA DE CERVEJA
}

\author{
Edson Roberto Scharf \\ Doutor em Engenharia e Gestão do Conhecimento pela Universidade Federal de Santa Catarina - \\ UFSC \\ Docente do Programa PPGA da Universidade de Blumenau - FURB \\ E-mail: talentto@terra.com.br (Brasil)
}

\author{
Amélia Silveira \\ Doutora em Ciências da Comunicação pela Escola de Comunicações e Artes da USP - ECA/USP \\ Docente do Programa PPGA da Universidade de Blumenau - FURB \\ E-mail: ameliasilveira@gmail.com (Brasil)
}

\section{RESUMO}

As marcas são fatores críticos de sucesso para as organizações e quando bem administradas tornamse valiosos ativos financeiros e estratégicos. O presente estudo tem como foco a marca, e como objetivo compreender sua importância no processo de compras business-to-business. Mais especificamente, o trabalho buscou conhecer a motivação dos clientes na aquisição da marca, saber se os esforços de comunicação interferem na decisão de compra e compreender a importância da marca no processo de compra. Por meio de pesquisa realizada junto aos distribuidores da cerveja Krill na região Sul do Brasil, concluiu-se que a marca tem importância no processo de compras business-to-business, proporcionando maior volume de vendas e lucratividade. No entanto, ficou evidente que a falta de investimentos na mídia e demais esforços de comunicação dificultam a valorização da marca. Diante deste cenário, conclui-se que o processo de branding pode alavancar o relacionamento entre os distribuidores e a marca, ao proporcionar condições para a criação de vantagens competitivas sustentáveis.

Palavras-chave: Branding; Competitividade; Marketing; Valor da Marca.

REMark - Revista Brasileira de Marketing, São Paulo, v. 8, n. 1, p 24-42, jan./jun. 2009. 


\section{INTRODUÇÃO}

As marcas são ativos valiosos para as organizações, tanto do ponto de vista financeiro quanto estratégico. Muitas empresas em expansão pagam altos valores pela aquisição de marcas líderes. Marcas têm influência direta no processo de decisão de compra dos consumidores (AAKER, 2007; KOTLER; KELLER, 2006). Os contínuos esforços de marketing no sentido de desenvolver, posicionar e diferenciar a marca na mente dos consumidores, facilitando a tomada de decisão compõem o processo denominado branding (SCHARF, 2007; TAVARES, 2008).

Com a globalização, as marcas começaram a ter maior relevância devido ao acesso mais fácil a portfólios completos de produtos. A internet, as filiais ou as importadoras permitiram às pessoas obter informações mais precisas em relação à marca.

Empresas tradicionais, que antes se baseavam na capacidade produtiva, também iniciaram um processo de desenvolvimento, posicionamento e gestão de marcas muito forte. Ao se considerar que a era do conhecimento está solidificada, o processo de branding toma a frente nas atividades mercadológicas, facilitando as ações das organizações.

A partir dessa constatação, o presente trabalho buscou realizar um estudo que tem como foco a marca, para compreender a motivação de compra e o entendimento dos clientes business-tobusiness da região Sul do país na aquisição da marca Krill.

O estudo objetiva compreender a importância da marca no processo de compra business-tobusiness, a partir de uma marca de cerveja; verificar o que motiva os clientes a adquirir a marca e também se os esforços de comunicação interferem na decisão de compra. Com base no exposto, compreender a relevância dos esforços de branding como fio condutor na construção de vantagens competitivas sustentáveis.

Para a elaboração do estudo, realizou-se levantamento bibliográfico e, em seguida, pesquisa com clientes distribuidores da marca Krill atuantes na região Sul do Brasil, nos Estados do Paraná, do Rio Grande do Sul e de Santa Catarina.

Foi possível compreender a importância da marca no processo de compra business-tobusiness e observar a necessidade de esforços de comunicação para lembrança e valorização da marca.

REMark - Revista Brasileira de Marketing, São Paulo, v. 8, n. 1, p 24-42, jan./jun. 2009. 


\title{
2 MARKETING
}

A competição acirrada entre as organizações permitiu que os clientes tivessem maior liberdade de escolha, fazendo com que as empresas direcionassem sua atenção para a compreensão das necessidades e desejos dos consumidores. Como são necessárias estratégias para que o produto seja percebido e lembrado por consumidores e clientes, esforços dirigidos à gestão das marcas são maneiras mais duradouras de inserir na mente dos consumidores um posicionamento adequado.

Nas palavras de Kotler e Keller (2006, p. 4), "Marketing é um processo social pelo qual indivíduos e grupos obtêm o que necessitam e desejam por meio da criação da oferta e da livre troca de produtos e serviços de valor com outros". O marketing muitas vezes é interpretado como a arte de vender produtos.

No entendimento de Dias (2006):

O conceito de marketing pode ser entendido como a função empresarial que cria continuamente valor para o cliente e gera vantagem competitiva duradoura para a empresa, por meio da gestão estratégica das variáveis controláveis de marketing: produto, preço, comunicação e distribuição (DIAS, 2006, p. 2).

Scharf (2007) amplia a extensão do conceito de marketing ao trazer as relações após a venda, a possibilidade de relacionamento e o uso do conhecimento:

\begin{abstract}
Marketing é o processo que observa e segmenta o mercado, compreende seus comportamentos, identifica as necessidades e desejos, pensa em soluções, viabiliza produtos éticos que contenham valor e que permitam ao consumidor sentir-se bem (bens físicos ou serviços, inclusas aqui as ideias e participações), comunica o conceito e seus benefícios, facilita a compra (distribuição+preço+venda), se relaciona com o cliente após essa aquisição e, baseado nas ações anteriores, administra o conhecimento adquirido para criar vantagens competitivas sustentáveis e futuras ações mercadológicas (SCHARF, 2007, p. 17).
\end{abstract}

O mercado, segundo Dias (2006), consiste basicamente em um conjunto de pessoas ou organizações cujas necessidades podem ser satisfeitas por um produto ou serviço e que estas disponham de renda para adquiri-los.

Assim, o marketing contribui com a realização de estratégias que entregam valor aos mercados (WOODRUFF, 1997). É necessário ter consciência de que o comprador decide comparando os benefícios oferecidos com os custos de aquisição da oferta. Após, confronta o valor dessa oferta com o valor das outras, fazendo por fim a sua escolha (OLIVER, 1999).

REMark - Revista Brasileira de Marketing, São Paulo, v. 8, n. 1, p 24-42, jan./jun. 2009. 
Segundo Scharf (2007), o conceito de valor é relativo a cada pessoa. E argumenta que quanto mais valor a empresa conseguir colocar no seu produto, mais fácil ela cria uma posição estratégica que seja, de fato, defensível. Zeithaml e Bitner (2003) corroboram com a ideia ao dizer que valor é toda avaliação feita pelo cliente sobre a utilidade do produto, baseada na percepção do que é recebido em relação ao que é dado.

\title{
3 RELACIONAMENTO
}

No mercado existem dois tipos de clientes: as pessoas físicas e as pessoas jurídicas. Para fins deste estudo, consumidor é representado por indivíduos ou grupos que compram para consumo próprio, em uma relação denominada business-to-consumer, e cliente é representado por consumidores empresariais, na relação denominada business-to-business.

Normalmente o que conta para os clientes empresariais é poder utilizar o produto para gerar valor agregado e assim conseguir conduzir uma empresa bem-sucedida. Quando a experiência de um produto não consegue atrair clientes finais, a experiência do cliente empresarial sairá prejudicada e ele tenderá a abandonar as vendas desse produto (SCHMITT, 2004).

Para Grönroos (1993):

\begin{abstract}
Com muita frequência pessoas da organização encaram os clientes como um fenômeno abstrato ou uma massa que está sempre presente em algum lugar. Os clientes são vistos em termos de números. Quando alguém deixa de ser um cliente, há sempre novos clientes potenciais para tomar o seu lugar. Tanto cliente como indivíduos e organizações são apenas números. Na realidade, isto não é verdade. Cada cliente cria um relacionamento com o fornecedor, que a empresa tem que desenvolver e manter. Os relacionamentos com os clientes não são coisas que estão ali garantidas; eles devem ser conquistados. E o mesmo se aplica aos relacionamentos com distribuidores, fornecedores e outros públicos (GRÖNROOS, 1993, p. 164).
\end{abstract}

Os conceitos de promessa e, de troca são elementos igualmente importantes do relacionamento com o cliente. Promessas sobre trocas que irão ocorrer são dadas mutuamente no relacionamento, e essas promessas são realizadas e cumpridas com vários tipos de trocas que ocorrem. Ao estabelecer e manter relacionamentos com o cliente, a empresa vendedora concede uma série de promessas referentes, por exemplo, a mercadorias, serviços ou sistemas de bens e serviços, soluções financeiras, administração de materiais, transferência de informações, contatos sociais e uma gama de comprometimentos futuros. Por outro lado, o comprador concede outro

REMark - Revista Brasileira de Marketing, São Paulo, v. 8, n. 1, p 24-42, jan./jun. 2009. 
conjunto de promessas relativas ao seu comprometimento nessa relação. Ao final, as promessas entre ambos devem ser mantidas, se quiserem que o relacionamento perdure e se desenvolva ainda mais para benefício mútuo (GRÖNROOS, 1993).

Aaker (2007) afirma que o relacionamento marca-cliente pode ser baseado em uma proposta de valor, ou ainda diretamente da identidade da marca, em especial quando a proposta de valor não capta de forma eficiente o relacionamento. Muitos relacionamentos marca-cliente emergem quando a marca é considerada uma organização ou pessoa, em vez de produto. Os relacionamentos entre uma marca e os clientes podem ser baseados em uma série de sensações positivas (como admiração, amizade, diversão e pertencimento a uma mesma comunidade) que podem ser exatamente conceituadas em termos de proposta de valor.

Nas palavras de Aaker (2007):

A proposta de valor de uma marca é uma afirmação dos benefícios funcionais, emocionais e de autoexpressão oferecidos pela marca que proporcionam valor ao cliente. A proposta de valor eficiente deverá conduzir a um relacionamento marca-cliente e impulsionar as decisões de compra (AAKER, 2007, p. 104).

\section{BRANDING}

Para Kotler e Keller (2006) branding significa dotar produtos e serviços com o poder de uma marca. Está totalmente relacionado a criar diferenças. Para colocar uma marca em um produto, é necessário ensinar aos consumidores quem é o produto - batizando-o e utilizando outros elementos de marca que ajudem a identificá-lo -, bem como a que ele se presta e por que o consumidor deve de interessar por ele. O branding diz respeito a criar estruturas mentais e ajudar o consumidor a organizar seu conhecimento sobre produtos e serviços, de forma que torne sua tomada de decisão mais esclarecida, e, nesse processo, gere valor para a empresa.

Para Keller e Machado (2006), o termo branding pode ser definido como o conjunto de atividades que visa otimizar a gestão das marcas de uma organização como diferencial competitivo. Envolve atividades como design, naming, proteção legal, pesquisa de mercado, avaliação financeira, posicionamento e comunicação. Fazer branding requer a integração de um conjunto de atividades em que é necessário comprometimento e visão de longo prazo.

REMark - Revista Brasileira de Marketing, São Paulo, v. 8, n. 1, p 24-42, jan./jun. 2009. 
Para Scharf (2007) pode-se denominar branding a evolução de um processo de comunicação integrada em que várias ferramentas são pensadas, desenvolvidas, aplicadas e controladas visando à gestão de marcas para um retorno ótimo dos investimentos.

Ainda segundo o autor, marcas são o resultado das experiências, das percepções, das sensações, dos contatos e das avaliações dos consumidores. Assim, consciente ou inconscientemente, “está-se avaliando a marca, mesmo sem ter dado um sentido prático e objetivo a ela" (SCHARF, 2007, p. 76).

Segundo Aaker (2007), a identidade de uma marca proporciona sentido, finalidade e significado à marca. E ainda, completa o autor, a identidade da marca é para a estratégia da marca o que o objetivo estratégico é para a estratégia empresarial.

Nas palavras de Aaker (2007):

\begin{abstract}
A identidade da marca é um conjunto exclusivo de associações com a marca que o estrategista de marcas ambiciona criar ou manter. Essas associações representam aquilo que a marca pretende realizar e implica uma promessa aos clientes, feita pelos membros da organização. A identidade da marca deve ajudar a estabelecer um relacionamento entre a marca e o cliente por meio de uma proposta de valor envolvendo benefícios funcionais, emocionais ou de autoexpressão (AAKER, 2007, p. 80).
\end{abstract}

A estratégia de branding de uma empresa reflete o número e a natureza dos elementos de marca comuns e características que se aplicam aos diferentes produtos por ela comercializados. E, em função da falta de um processo adequado de branding, Tybout (2006) diz que criar e construir marcas são “...os dois maiores desafios enfrentados pelos gerentes. Para cada Starbucks ou Nike há dezenas de marcas fracassadas".

Segundo Moreira (2004), ao se decidir pelo uso de marcas, as organizações devem optar entre alguns caminhos estratégicos que envolvem sua utilização, como: marca guarda-chuva, marca individual e marca mista. Além dessas estratégias, existem outras, como a extensão de marca e o licenciamento da marca.

O posicionamento está sempre presente na análise das marcas e pode ser considerado decisivo na sua gestão. O conceito de posicionamento refere-se à criação de uma posição ou imagem para a marca na mente do consumidor que seja diferenciada em relação às marcas da concorrência, a fim de obter vantagem competitiva. A posição na mente é a imagem de marca formada a partir da avaliação do produto em relação a seus concorrentes (DIAS, 2006).

Para Tybout (2006), o posicionamento de uma marca é desenvolvido pelo gerente de marca e está baseado na ideia de metas e percepções de um grupo-alvo de consumidores. Aaker (2007)

REMark - Revista Brasileira de Marketing, São Paulo, v. 8, n. 1, p 24-42, jan./jun. 2009. 
afirma que tentar desenvolver uma marca forte pode ter a dificuldade de pressões e barreiras, tanto internas quanto externas, como tendência contra a inovação ou pela modificação de estratégias, ou a pressão para competir por preço.

\section{MÉTODO DA PESQUISA}

O trabalho caracteriza-se como uma pesquisa exploratória. Segundo Cooper e Schindler (2003), uma pesquisa exploratória inicia-se com a busca de dados publicados em literatura secundária. $\mathrm{Na}$ pesquisa exploratória são aplicáveis tanto técnicas qualitativas como as quantitativas, embora a exploração se baseie mais nas técnicas qualitativas. Este estudo foi dividido em duas fases: uma exploratória, de natureza qualitativa, na qual se desenvolveu uma compreensão inicial a respeito do problema, e outra descritiva, de natureza quantitativa, em que foi possível quantificar as informações obtidas (MALHOTRA, 2001).

Inicialmente, foi realizada a fundamentação teórica, desenvolvendo o tema do trabalho para seu entendimento e compreensão. Para Dencker (2003), nenhuma pesquisa se inicia do nada, mas de um processo cumulativo de aquisição de conhecimento e se enquadra em um modelo teórico a partir do qual se fazem deduções. A teoria é a base sobre a qual desenvolve-se o modelo de explicação que se testa com a pesquisa. Marconi e Lakatos (2005, p. 227) afirmam que "a citação das principais conclusões a que outros autores chegaram permite salientar a contribuição da pesquisa realizada, demonstrar contradições ou reafirmar comportamentos e atitudes".

Segundo Cooper e Schindler (2003), a coleta de dados pode variar desde uma simples observação até um levantamento grandioso. Os dados podem ser caracterizados por sua abstração, verificabilidade, evasividade e proximidade com o fenômeno. Os dados foram obtidos através de questionário aplicado junto a todos os clientes (pessoas jurídicas, na condição de distribuidores da marca Krill) na Região Sul, por meio de e-mail ou fax. A marca é pertencente a Cervejaria Krill, presente no mercado há 12 anos, com sede administrativa em Socorro, São Paulo.

Conforme Dencker (2003), o objetivo da análise dos dados é reunir as observações de forma coerente e organizada, fazendo conexão entre os dados coletados e o conhecimento existente, para que seja possível responder ao problema da pesquisa. Para melhor visualização e compreensão dos dados e das informações apresentadas foram utilizados gráficos, além da análise e interpretação e a ligação dos dados com a teoria. Nem todas as questões foram apresentadas, pois algumas não serviam ao objetivo deste estudo.

REMark - Revista Brasileira de Marketing, São Paulo, v. 8, n. 1, p 24-42, jan./jun. 2009. 


\section{APRESENTAÇÃO E ANÁLISE DOS RESULTADOS}

Para responder aos objetivos iniciais propostos para este trabalho, foi realizada pesquisa junto ao total de distribuidores da marca Krill, da Cervejaria Krill, nos Estados do Paraná, do Rio Grande do Sul e de Santa Catarina. Os dados e a avaliação referentes são apresentados a seguir.

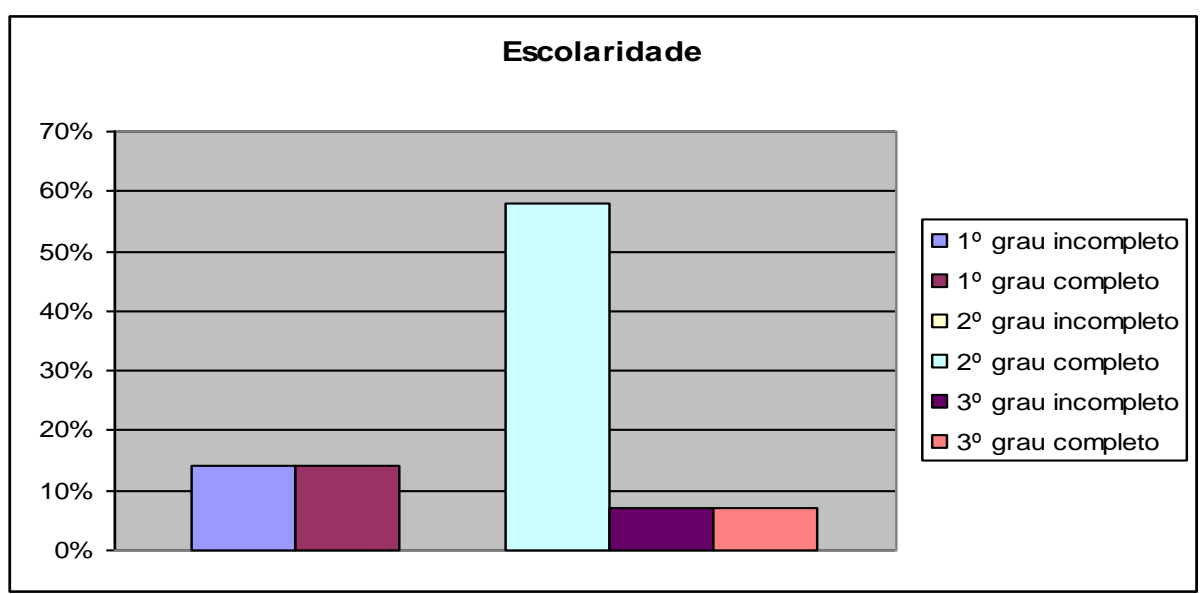

Gráfico 1 - Nível de escolaridade dos respondentes

Observa-se no Gráfico 1 que pouco mais da metade dos entrevistados possuem o segundo grau completo, aproximadamente $1 / 4$ possuem até o primeiro grau de escolaridade e os demais entrevistados possuem o terceiro grau.

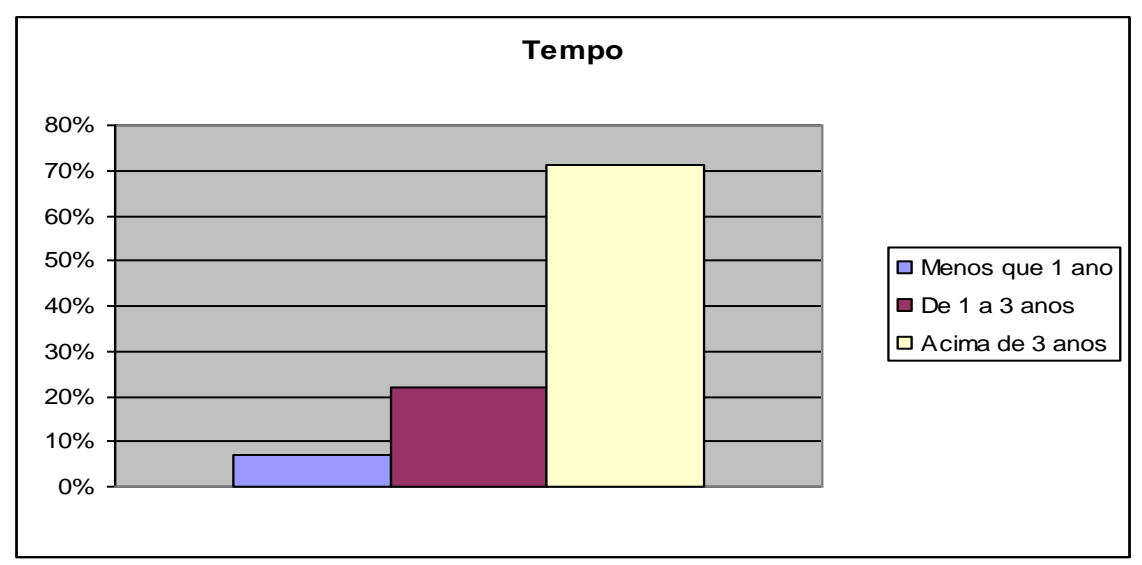

Gráfico 2 - Tempo que o cliente trabalha com a marca Krill

No Gráfico 2 verifica-se que grande parte dos entrevistados trabalha e representa a marca Krill há mais de três anos no mercado e quase 1/3 trabalha há menos de três anos com a marca.

REMark - Revista Brasileira de Marketing, São Paulo, v. 8, n. 1, p 24-42, jan./jun. 2009. 


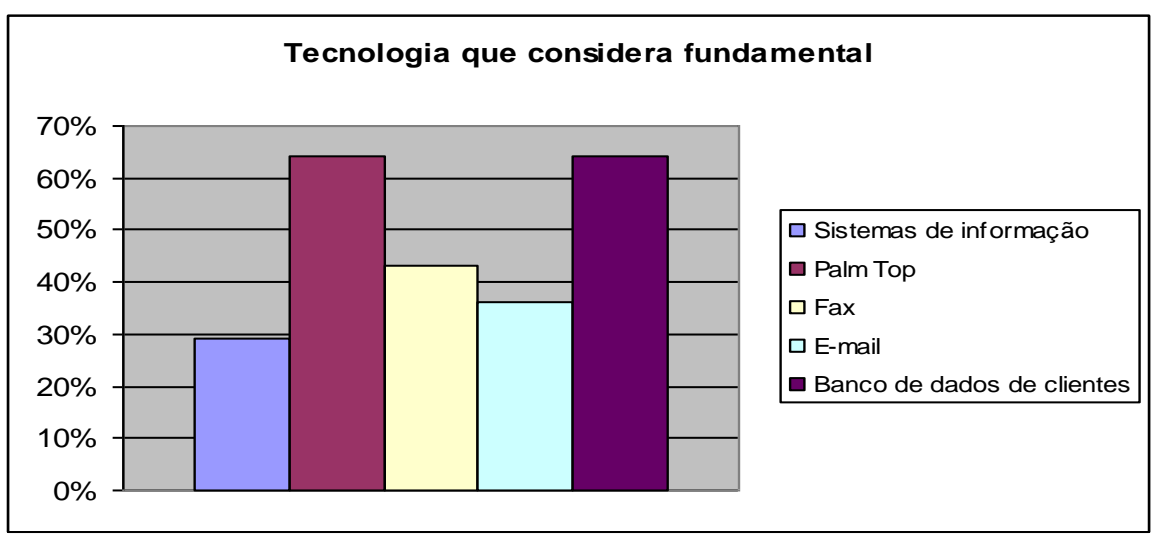

Gráfico 3 - Tecnologia que considera fundamental

No Gráfico 3 vê-se a tecnologia que o entrevistado considera fundamental para o desempenho dos trabalhos na sua empresa: a maioria dos entrevistados respondeu palm top (nome genérico para o hand held, consolidado a partir da marca). A tecnologia da informação e da comunicação (TICs), mesmo sendo considerada de importância no meio empresarial como ferramenta que dá suporte a decisões estratégicas, é utilizada por apenas 1/3 dos entrevistados.

Figueiredo (2005) lembra que adaptação e inovação surgem no contexto empresarial não mais como opção, mas como obrigação da empresa moderna, inserida em um ambiente hostil e competitivo que necessita constante revisão das estratégias. A aprendizagem e a inovação são caminhos que criam valor e diferenciais duráveis para as organizações (KUSUNOKI, 2008; TARAPANOFF, 2006).

Para Scharf (2006), a gestão do conhecimento é o processo adequado para que informações internas e externas, tácitas ou expressas, possam ser canalizadas para resultados ótimos. Um dos formatos mais adotados nas empresas para gerar informações, a fim de facilitar a tomada de decisões e permitir o acompanhamento de resultados no mercado, é o Sistema de Informações Gerenciais. Ele deve conter informações externas, eventos da concorrência direta ou indireta e tendências do mercado de atuação, e também conter informações internas como dados relevantes e informações que tenham ligação com o negócio da empresa e que permitam entender alguns dos retornos que estejam ocorrendo por parte dos consumidores.

Portanto, para que os entrevistados sejam competitivos no mercado, o uso da tecnologia é fundamental para a sua sobrevivência e seu crescimento.

REMark - Revista Brasileira de Marketing, São Paulo, v. 8, n. 1, p 24-42, jan./jun. 2009. 


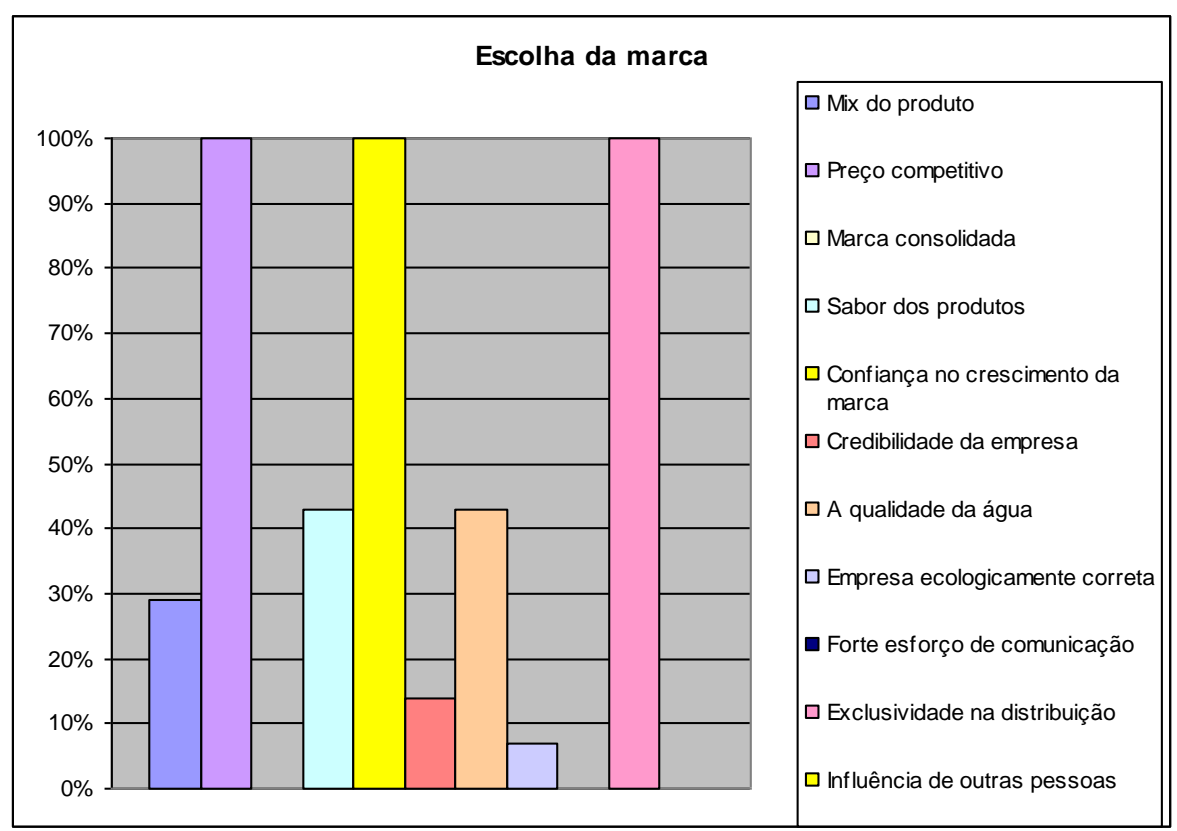

Gráfico 4 - Escolha da marca

Perguntou-se aos entrevistados quais as motivações que fizeram com que sua empresa optasse pela exclusividade na distribuição da marca Krill. Observa-se no Gráfico 4 que preço competitivo, confiança no crescimento da marca e exclusividade na distribuição foram, em sua totalidade, apontadas como as principais motivações. Em seguida, com um pouco menos da metade, o sabor dos produtos e a qualidade da água com a qual a cerveja é produzida. $\mathrm{O}$ mix de produtos que a Cervejaria Krill oferece, a credibilidade da empresa no mercado e a atuação ecologicamente correta tiveram pouca relevância. A marca consolidada no mercado, forte esforço de comunicação de mídia e material de merchandising e influência de outras pessoas não tiveram relevância na decisão dos entrevistados. Estes itens, como se confirmará a seguir, não têm relevância porque não são trabalhados de forma abrangente na comunicação da empresa produtora da cerveja.

Segundo Schmitt (2004), os clientes empresariais trabalham em benefício de uma empresa para satisfazer uma meta de negócios.

O preço competitivo facilita a realização das vendas, mas também prejudica a lucratividade da empresa e induz os consumidores a relacionar a marca com um produto de baixa qualidade (BEULKE, 2009). A exclusividade na distribuição garante aos entrevistados o direito de vender exclusivamente a marca em determinada região. Para eles, trata-se de uma vantagem mas não para consumidores finais. A confiança no crescimento da marca torna-se o principal fator que sustenta expectativas de aumento de volume de vendas, lucratividade e sucesso nos negócios.

REMark - Revista Brasileira de Marketing, São Paulo, v. 8, n. 1, p 24-42, jan./jun. 2009. 


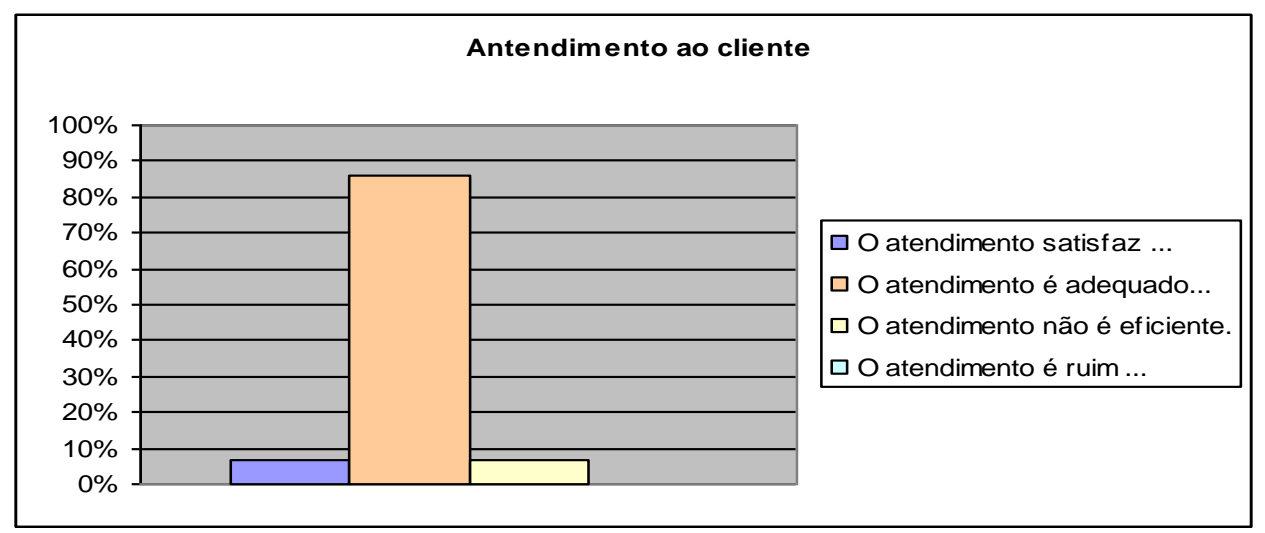

Gráfico 5 - Atendimento ao cliente

Ao serem questionados sobre o atendimento que recebem da Cervejaria Krill e do representante da sua área, a maioria dos entrevistados afirma que o atendimento é adequado, mas poderia melhorar.

O serviço prestado por uma organização pode variar seu desempenho. Segundo os autores, a região formada pelo reconhecimento dessa variação e pela disponibilidade em aceitá-la chama-se Zona de Tolerância. Caracteriza-se pela expectativa de serviços dos consumidores por um espectro de níveis entre o serviço desejado que reflete o que os clientes querem, e o adequado, que mostra o que os clientes estão dispostos a aceitar (ZEITHAML; BITNER, 2003).

Scharf (2006) afirma que é preciso construir relacionamentos duradouros entre a empresa e seus clientes, melhorando a resposta entre eles e aumentando a possibilidade de lealdade. Neste caso, está ocorrendo um atendimento adequado, no qual os clientes estão dispostos a aceitar, mas não está ocorrendo um atendimento desejado, que reflete o que os clientes querem ou como gostariam que fosse.

REMark - Revista Brasileira de Marketing, São Paulo, v. 8, n. 1, p 24-42, jan./jun. 2009. 


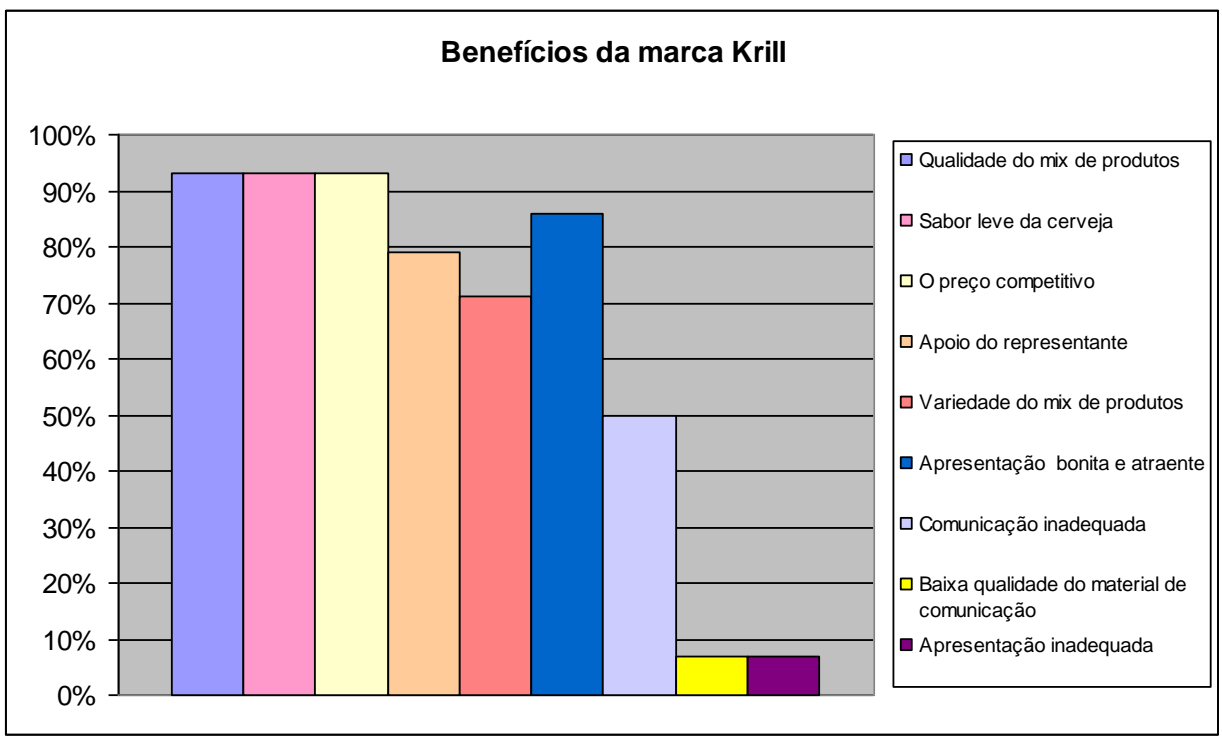

Gráfico 6 - Benefícios da marca Krill

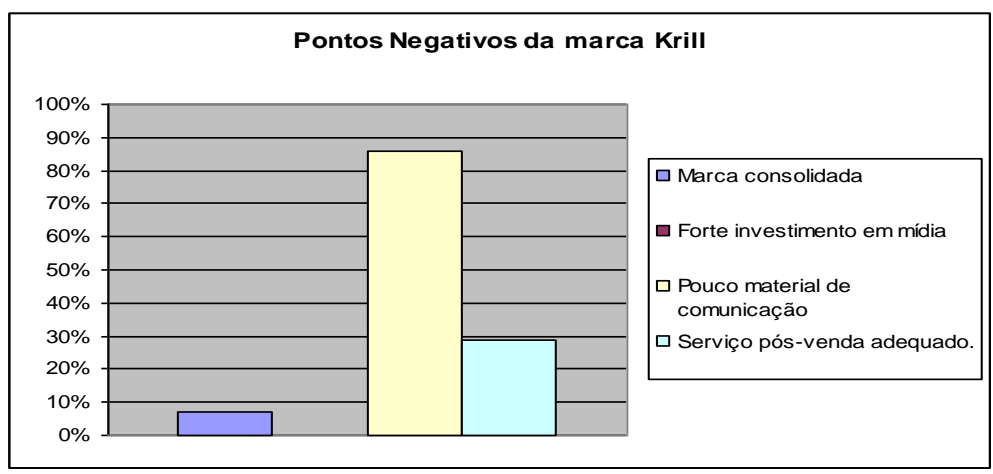

Gráfico 7 - Pontos negativos da marca Krill

Os entrevistados deveriam avaliar os benefícios e pontos negativos da marca Krill, apresentados nos Gráficos 6 e 7.

Grande parte dos entrevistados destaca como benefícios da marca Krill a qualidade dos produtos, sabor leve da cerveja, apresentação dos produtos adequada, boa qualidade do material de comunicação e o preço competitivo. A maioria também afirma que a apresentação dos produtos é atraente, há apoio do representante junto ao distribuidor e o mix dos produtos apresenta variedade. Como pontos negativos destacam-se a marca não consolidada no mercado, não há investimento em mídia, pouco material de comunicação e serviço pós-venda inadequado. Com relação ao esforço

REMark - Revista Brasileira de Marketing, São Paulo, v. 8, n. 1, p 24-42, jan./jun. 2009. 
inadequado de comunicação da marca, metade apresentou respostas positivas e outra metade negativas.

Segundo Telles (2003), a marca deve ligar-se a algumas características relacionadas à criação e à manutenção de valor percebido pelo cliente/consumidor, pois é mediante a marca que a empresa também atende as expectativas dos consumidores, prometendo e entregando ao cliente um

valor superior ao encontrado no mercado. Já Scharf (2006) destaca que alguém decide pela compra de um produto quando ele é bem elaborado, tem um preço percebido como justo, é encontrado facilmente e sua propaganda convence e cria apelo para a marca.

Conforme destacado pelos entrevistados, a marca Krill possui muitos benefícios. No entanto os pontos negativos impedem o crescimento e o desenvolvimento da marca no mercado. Falta atenção quanto à comunicação da marca. Neste estágio, o branding é o fator que pode diferenciar a marca no seu segmento, ao se adotar processos dirigidos para o seu correto crescimento (SCHARF, 2007; TYBOUT, 2006).

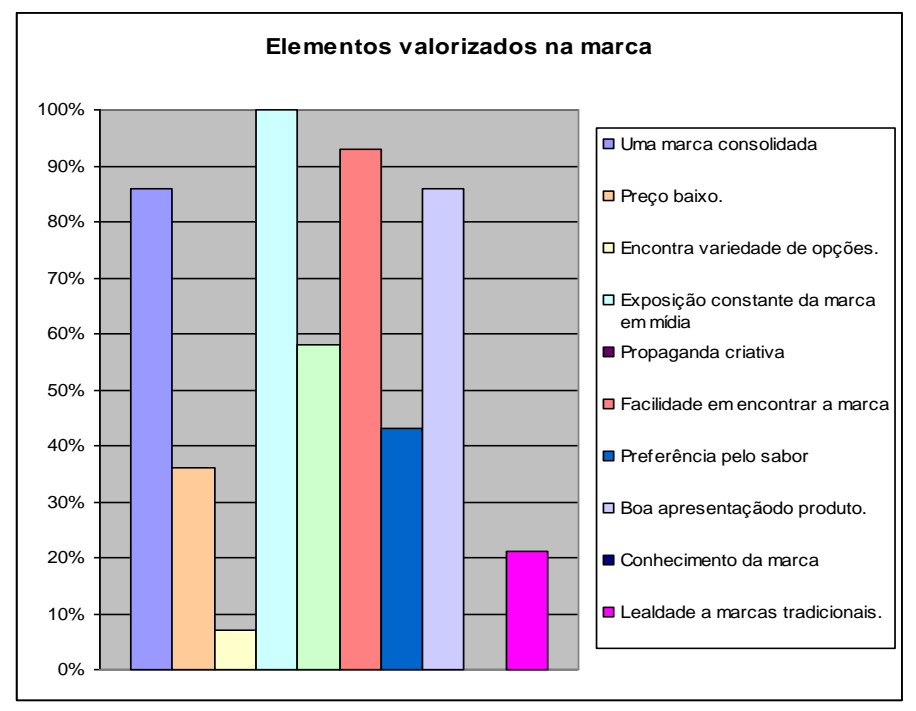

Gráfico 8 - Elementos valorizados na marca

Os entrevistados foram questionados sobre seu entendimento de quais são os elementos valorizados pelo consumidor final na hora de decidir por uma marca de cerveja. Observa-se no Gráfico 8 que todos os entrevistados afirmaram que a exposição constante da marca na mídia, por meio de anúncios ou comerciais, de patrocínios, de eventos e do merchandising, é o elemento mais valorizado pelo consumidor final. A maioria afirmou também que a facilidade em encontrar a marca

REMark - Revista Brasileira de Marketing, São Paulo, v. 8, n. 1, p 24-42, jan./jun. 2009. 
em pontos de venda, ter uma marca consolidada, boa apresentação do produto (embalagem e rótulo) e propaganda criativa também são elementos valorizados pelo consumidor final. Menos da metade dos entrevistados considera a preferência pelo sabor, preço baixo, lealdade a marcas tradicionais e encontrar variedade de opções como elementos valorizados pelo consumidor final.

Segundo Scharf (2006), as marcas são avaliadas constantemente e independem de se dar um sentido prático à avaliação. Logo, se a marca é bem-vista pelos consumidores, o cliente terá maior comprometimento em trabalhar para a empresa.

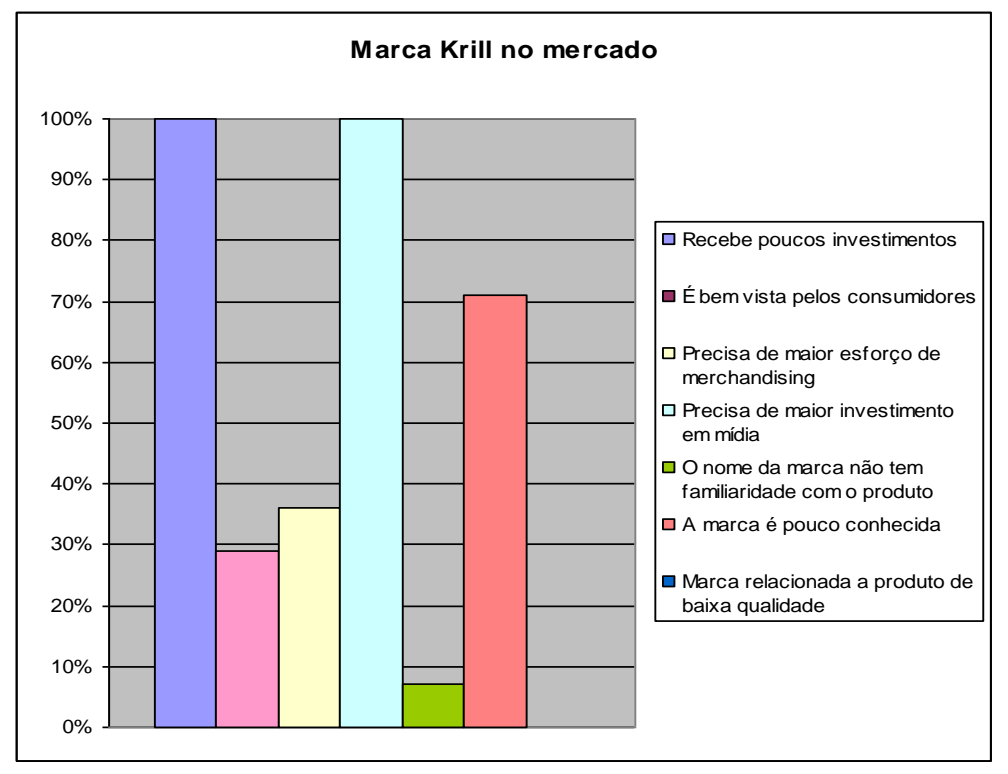

Gráfico 9 - Marca Krill no mercado

Perguntou-se aos entrevistados (Gráfico 9) o que veem e ouvem no mercado sobre a marca Krill. Todos responderam que a marca recebe poucos investimentos e acreditam que seria bemaceita se tivesse maior investimento em mídia. A maioria afirma que a marca é pouco conhecida no mercado. Menos da metade dos entrevistados afirma, também, que a marca é bem-vista pelos consumidores, que seria mais bem percebida se tivesse maior esforço em merchandising e que o nome da marca não transmite familiaridade com o produto que representa. Nenhum dos entrevistados declarou que a marca representa um produto de baixa qualidade no mercado.

Segundo Schultz e Barnes (2001), a propaganda é um meio de comunicação para criar e melhorar a imagem global da marca e seu posicionamento no mercado. A propaganda é vista como elemento criador e de sustentação da identidade da marca (AAKER, 2007; SCHARF, 2006), proporcionando a proteção de um guarda-chuva sob o qual se pode desenvolver esforços de comunicação dirigidos a grupos mais específicos de audiência (SCHULTZ; BARNES, 2001).

REMark - Revista Brasileira de Marketing, São Paulo, v. 8, n. 1, p 24-42, jan./jun. 2009. 


\section{CONSIDERAÇÕES FINAIS}

A marca é um fator crítico de sucesso às organizações. O impacto da marca pode ocasionar o sucesso para uma empresa, principalmente em termos econômicos, e o branding se destaca neste cenário, influenciando diretamente nas decisões estratégicas.

Com base nesta pesquisa, e para este caso, a marca assume importância no processo de compras business-to-business, na percepção dos clientes, ao proporcionar maiores volumes de venda e lucratividade. No entanto, fica evidente que falta à marca Krill apoio de mídia e esforços de comunicação com o objetivo de valorizar e tornar conhecida a marca. As vendas tornam-se mais difíceis, deixando os distribuidores insatisfeitos. Marcas de bens de consumo não podem prescindir de esforços dirigidos ao consumidor (AAKER, 2007; HOOLEY; SAUNDERS; PIERCY, 2005; TAVARES, 2008).

Uma marca consolidada transmite credibilidade e confiança aos seus consumidores e clientes, e isto é fundamental em um mercado onde se encontram disponíveis produtos de qualidade e marcas fortes. O processo de branding torna-se prioritário para a condução de ações visando ao desenvolvimento e à gestão eficiente da marca (LINDSTROM, 2007).

Particularmente com relação ao Gráfico 9 (menos da metade dos entrevistados considera a preferência pelo sabor, preço baixo, lealdade a marcas tradicionais como um dos elementos valorizados pelo consumidor final), a partir de um trabalho estruturado de branding é possível reverter uma situação consolidada, que é o segmento das grandes cervejas. A Skol é o exemplo mais interessante, pois durante aproximadamente cinco anos fez um trabalho nos bastidores junto ao seu público-alvo, com claras intenções de conquistar a liderança. Boas iniciativas de branding permitiram à marca a conquista e a manutenção de posições fortemente defensíveis (AAKER, 2007; LINDSTROM, 2007), mesmo sendo mais cara que as concorrentes mais próximas (TAVARES, 2008).

Apesar das dificuldades óbvias em relação ao poderio de mídias das marcas líderes, é possível esperar que um trabalho coerente e sólido permita à marca se posicionar entre as grandes marcas tradicionais. Para tal, e observando a análise do gráfico 9 (em que o nome da marca não transmite familiaridade com o produto que representa), é necessária a criação de uma identidade para a marca, ou seja, um conjunto de associações com ela que permita uma promessa aos consumidores finais (AAKER, 2007).

REMark - Revista Brasileira de Marketing, São Paulo, v. 8, n. 1, p 24-42, jan./jun. 2009. 
Ao mesmo tempo, e considerando a formação acadêmica relativamente baixa dos distribuidores, um plano estratégico de comunicação dirigido ao trade e com observação específica das tendências do segmento na atualidade, é uma ação imediata a ser tomada para servir como base de um processo mais abrangente de branding (HOOLEY; SAUNDERS; PIERCY, 2005; SCHARF, 2007). Ainda com relação aos clientes, pode-se aproveitar o momento para avaliar o sistema de informações gerenciais da Krill e aperfeiçoá-lo, tornando-o mais amigável para uso constante.

Por último, o branding precede de uma atitude aberta de compartilhamento de conhecimento. A cada evento ocorrido no mercado, nova possibilidade aberta ou novo problema percebido, é fundamental que estas informações sejam repassadas à empresa para uma tomada de decisão mais adequada e a manutenção de uma marca forte.

\section{REFERÊNCIAS}

AAKER, D. Construindo marcas fortes. Porto Alegre: Bookman, 2007.

BEULKE, R. Preço estratégico no Marketing. São Paulo: Saraiva, 2009.

COOPER, D. R.; SCHINDLER, P. S. Métodos de pesquisa em administração. 7. ed. Porto Alegre: Bookman, 2003.

DENCKER, A. F. M. Métodos e técnicas de pesquisa em turismo. 7. ed. São Paulo: Futura, 2003.

DIAS, S. R. Gestão de Marketing. São Paulo: Saraiva, 2006.

FIGUEIREDO, S. P. Gestão do conhecimento: estratégias competitivas para a criação e mobilização do conhecimento na empresa: como alavancar e multiplicar o capital intelectual e o conhecimento da organização. Rio de Janeiro: Qualitymark, 2005.

GRÖNROOS, C. Marketing: gerenciamento e serviços: a competência de serviços na hora da verdade. Rio de Janeiro: Campus, 1993.

HOOLEY, G. J.; SAUNDERS, J. A.; PIERCY, N. F. Estratégia de marketing e posicionamento competitivo. 3. ed. São Paulo: Pearson Prentice Hall, 2005.

REMark - Revista Brasileira de Marketing, São Paulo, v. 8, n. 1, p 24-42, jan./jun. 2009. 
KELLER, K. L.; MACHADO, M. Gestão estratégica de marcas. São Paulo: Pearson Prentice Hall, 2006.

KOTLER, F.; KELLER, K. L. Administração de marketing. 12. ed. São Paulo: Prentice Hall, 2006.

KUSUNOKI, K. Diferenciação de valor: organização do know-what para a inovação do conceito de produto. In: TAKEUCHI, I.; NONAKA, I. Gestão do conhecimento. Porto Alegre: Bookman, 2008. p. 142-164.

LINDSTROM, M. Brand sense: a marca multissensorial. Porto Alegre: Bookman, 2007.

MALHOTRA, N. Pesquisa de marketing: uma orientação aplicada. 3. ed. Porto Alegre: Bookman, 2001.

MARCONI, M. A.; LAKATOS, E. M. Fundamentos de metodologia científica. 6. ed. São Paulo: Atlas, 2005.

MOREIRA, T. J. C. Gerência de produtos. São Paulo: Saraiva, 2004.

OLIVER, R. L. Value as excellence in the consumption experience. In: HOLBROOK, M. B. Consumer value: a framework for analysis and research. New York: Routledge, 1999. p. 43-62.

SCHARF, E. R. Administração na propaganda: o planejamento e a gestão do conhecimento na administração aplicada à propaganda. Rio de Janeiro: Qualitymark, 2006.

SCHARF, E. R. Gestão do conhecimento aplicada ao marketing. Florianópolis: VisualBooks, 2007.

SCHMITT, B. H. Gestão da experiência do cliente: uma revolução no relacionamento com os consumidores. Porto Alegre: Bookman, 2004.

SCHULTZ, D. E.; BARNES, B. E. Campanhas estratégicas de comunicação de marca. Rio de Janeiro: Qualitymark, 2001.

TARAPANOFF, K. (Org.). Inteligência, informação e conhecimento em corporações. Brasília: IBICT/UNESCO, 2006.

TAVARES, M. C. Gestão de marcas: construindo marcas de valor. São Paulo: Harbra, 2008.

REMark - Revista Brasileira de Marketing, São Paulo, v. 8, n. 1, p 24-42, jan./jun. 2009. 
TELLES, R. Marketing empresarial. São Paulo: Saraiva, 2003.

TYBOUT, A. M. Branding. São Paulo: Atlas, 2006.

WOODRUFF, R. B. Customer value: the next source for competitive advantage. Journal of the Academy of Marketing Science, Greenvale, v. 25, n. 2, p. 139-153, 1997.

ZEITHAML, V. A.; BITNER, M. J. Marketing de serviços: a empresa com foco no cliente. Porto Alegre: Bookman, 2003.

THE RELATION BETWEEN DISTRIBUTORS AND A BEER BRAND

\begin{abstract}
The brand is a critical factor of success of the organizations. When well managed, they become financially valuable and strategic assets. This study aims at understanding the relation between the customers and the brand in the process of purchases business-to-business. It aimed at identifying the motivation of the customers in the acquisition of the brand to know if the communication efforts interfere with the decision of purchase, and to understand the importance of the brand in such process. Through research carried along the distributors of the Krill beer in the south region of Brazil, it is concluded that the brand has importance in the process of purchases business-tobusiness, providing bigger sales volume and profitability. However, it was evident that the lack of investments in the media and too much effort on communication make hard the brand valuation. Due to such scenery, one perceived that the branding process can empower the relationship between distributors and the beer brands.
\end{abstract}

Keywords: Brand Value; Branding; Competitiveness; Marketing.

REMark - Revista Brasileira de Marketing, São Paulo, v. 8, n. 1, p 24-42, jan./jun. 2009. 
Data do recebimento do artigo: 29/01/2009

Data do aceite de publicação: 17/03/2009

REMark - Revista Brasileira de Marketing, São Paulo, v. 8, n. 1, p 24-42, jan./jun. 2009. 